\title{
NÍVEL DE RUÍDO EM OPERAÇÕES AGRÍCOLAS: ESTUDO DE CASO COM ROÇADEIRAS MOTORIZADAS
}

\author{
Leonardo Lã Ferrari ${ }^{1}$ \\ Stéphanie Lã Ferrari ${ }^{2}$ \\ Jéferson Luiz Ferrari ${ }^{3}$
}

Resumo: Este trabalho teve como objetivo verificar os níveis de ruído emitidos por máquinas agrícolas durante operações de roçagem. Foram medidos e avaliados, em condições de campo, os níveis de ruído emitidos por um microtrator cortador de grama e por uma roçadeira costal motorizada. O equipamento empregado para se fazer a medição foi um decibelímetro digital Sound Meter. Foram feitas medições, antes e durante as operações. Durante as operações foram feitas medições até o raio de $15 \mathrm{~m}$, sempre do lado direito do operador. O método de avaliação foi baseado no nível de ruído, no posto de operação, de tratores e máquinas agrícolas (NBR 9.999/1987), que é a norma brasileira específica para a medida de ruído em tratores e seus efeitos sobre o tratorista, e na Norma 15/1978, do Ministério do Trabalho e do Emprego, que indica como prejudicial, o ruído de $85 \mathrm{~dB}$ para uma exposição máxima de 8 horas diárias. Antes das operações de roçagem, o nível sonoro da paisagem era de $30 \mathrm{~dB}$ e, durante as operações, o nível de ruído não ultrapassou o valor recomendado, apresentando valor máximo de $85 \mathrm{~dB}$.

Palavras-chave: Máquinas agrícolas; Ergonomia; Segurança do trabalho; Ruído ocupacional; Paisagem sonora.

\footnotetext{
${ }^{1}$ Aluno do Curso Técnico em Agropecuária/IFES-Campus de Alegre, Brasil. E-mail: ferrarileo14@hotmail.com.

2 Graduanda do Curso de Direito/Faculdade de Direito de Cachoeiro de Itapemirim, Brasil. E-mail: laferrari.stephanie@gmail.com.

3 Professor Orientador/IFES-Campus de Alegre, Brasil. E-mail: ferrarijluiz@gmail.com.
} 